\title{
The validity of a daytime ambulatory blood pressure to diagnose masked hypertension
}

\author{
Abdulhalim Jamal Kinsara, ${ }^{1}$ Ayman Hassan Elshiekh, ${ }^{1}$ Ahmed Mohamed Abuosa, ${ }^{1}$ Domenico Galzerano, ${ }^{2}$ \\ Mohammed Burhan Abrar ${ }^{3}$ \\ ${ }^{1}$ Ministry of National Guard-Health Affairs, King Saud Bin Abdulaziz University for Health Sciences, COM-WR, King \\ Abdullah International Medical Research Center; ${ }^{2}$ King Faisal Specialist Hospital and Research Centre and Alfaisal \\ University; ${ }^{3}$ Princess Noorah Oncology Centre, King Abdullah International Medical Research Center, King Saud Bin \\ Abdulaziz University for Health Sciences, Jeddah, Saudi Arabia
}

Correspondence: Abdulhalim Jamal Kinsara, FRCP. Department of Cardiology, Ministry of National Guard Health Affair, King Saud Bin Abdulaziz University for Health Sciences, COM-WR, King Abdullah International Medical Research Center, Mail code 6599, P.O. Box 9515, Jeddah 21423, Saudi Arabia. Tel.: 966569968182.

E-mail: akinsara@yahoo.com

Key words: Masked hypertension; ambulatory BP monitoring; office blood pressure; daytime blood pressure; 12h- ambulatory BP.

Conflict of Interest: The authors declare no conflict of interest.

Funding: The study did not receive specific funding, but was performed as part of the employment of the authors, at King Saud bin Abdulaziz University for Health Sciences.

Declaration of patient consent and availability of data and materials: The authors certify that they have obtained patient consent forms. The patient's name and initials would not be published and conceal his identity. The data used to support the findings of this study are restricted by the King Abdullah International Medical Research Center Institution Review Board in order to protect PATIENT PRIVACY. Data are available from the Institutional Review Board irb@ngha.med.sa or via the corresponding author, for researchers who meet the criteria for access to confidential data.

Contributions: Concept - AA, AK. Design - AA,AK,MA Supervision - AA,AK,AE Fundings - None; Materials - Not applicable; Data collection \&/or processing - AA,AK,AE.; Analysis \&/or interpretation AA,AK,AE,MA; Literature search - AA,AK,MA Writing DG,AA,AK,MA; Critical review - AA,AK,AE ,MA,DG. All the authors have read and approved the final version of the manuscript and agreed to be accountable for all aspects of the work.

Received for publication: 30 April 2020.

Accepted for publication: 3 June 2020.

${ }^{\circ}$ Copyright: the Author(s), 2020

Licensee PAGEPress, Italy

Monaldi Archives for Chest Disease 2020; 90:1356

doi: 10.4081/monaldi.2020.1356

This article is distributed under the terms of the Creative Commons Attribution Noncommercial License (by-nc 4.0) which permits any noncommercial use, distribution, and reproduction in any medium, provided the original author(s) and source are credited.

\begin{abstract}
Masked hypertension ( $\mathrm{MH}$ ) is traditionally diagnosed with 24hour ambulatory blood pressure monitoring (24-ABPM). This is relatively costly and could cause discomfort during the night. We studied the validity of daytime ABP (DT-ABPM) in young National Guard soldiers and determined the prevalence in comparison to the standard 24-ABPM.

A prospective study of 196 soldiers aged 21-50 years, without a history of hypertension or antihypertensive medication use. Each participant was fitted with a 12h-ABPM. Patients were diagnosed with $\mathrm{MH}$ if the office blood pressure (OBP) was $<140 / 90 \mathrm{mmHg}$ and the average DT-ABPM was $\geq 135 / 85 \mathrm{mmHg}$.

By pairing the average OBP with the $12 \mathrm{~h}-\mathrm{ABPM}$, the prevalence of MH was estimated as 18/196 (9.2\%), the SBP MH (systolic blood pressure) of $8.2 \%$ and the DPB MH (diastolic blood pressure) of $3.1 \%$. When we compared the daytime prevalence with the $24 \mathrm{~h}-\mathrm{ABPM}$, and the average OBP, the prevalence of $\mathrm{MH}$ was $29 / 196(14.8 \%)$. No statistically significant difference was noted (kappa $=0.74 ; 95 \%$, CI: 0.59 to 0.88 ).

We conclude that DT-ABPM is a good method and convenient to detect $\mathrm{MH}$, with no statistically significant difference when compared to the $24 \mathrm{~h}$-ABPM. The prevalence of $\mathrm{MH}$ in young healthy soldiers was unexpectedly high.
\end{abstract}

\section{Introduction}

Hypertension is an important risk for cardiovascular disease and remains a major public health burden globally $[1,2]$. The prevalence of hypertension varies widely depending on the geographical location, demographic, socioeconomic, and environmental factors. As an example, a systematic review reported the overall prevalence of hypertension in the Middle East as $21.7 \%$ (95\%, CI: 18.7-24.9) [3]. ABPM is useful in many situations, including evaluating the white-coat syndrome, resistance hypertension, masked hypertension and labile blood pressure (BP) [4].

ABPB do have disadvantages if compared to office or home $\mathrm{BP}$ recordings, which precludes its widespread use in general practice. These disadvantages include cost, a long waiting list as well as patient discomfort due to wearing the equipment for a 24-hour period during both waking and sleeping hours. Although patient discomfort appears minimal, it has been well documented. [5]. 
The aim of our study was to decide whether a shortened (12hours) time of ABPM could reflect the overall mean BP obtained from a 24-hour ABPM.

\section{Methods}

Healthy male soldiers, aged 21-50 years, were randomized to a prospective three-year study conducted as previously described [6]. The study was approved by the Institutional Review Board of King Abdullah International Medical Research Center. Patients provided written informed consent to participate in the study.

MH was defined as patients with an OBP of $<140 / 90 \mathrm{mmHg}$ and the daytime average blood $\geq 135 / 85 \mathrm{mmHg}[7,8]$. Data were analysed using the Statistical Package for the Social Sciences (SPSS) software version 24.0 for Windows (SPSS Inc., IL, USA). A P-value $\square 0.05$ was considered statistically significant.

\section{Results}

The mean age of the group diagnosed with $\mathrm{MH}$, using the DTABPM, were older than the normotensive group, 36.3 vs. 32.4 years $(\mathrm{P}=0.018)$. Comparing the systolic $\mathrm{MH}$ group with the systolic normotensive group, the mean age was 35.8 years vs. 32.5 years $(\mathrm{P}=0.042)$ and for the diastolic $\mathrm{MH}$ group compared to the diastolic normotensive group, 39.3 years and 32.4 years respectively $(\mathrm{P}=0.012)$, Table 1 .

A marked difference was noted between the mean OBP and mean DT-ABPM methods. The mean systolic OBP compared to the DT$\mathrm{ABPM}$ was $121.5 \pm 8.4$ and $138.9 \pm 4.8 \mathrm{mmHg}(\mathrm{P}<0.001)$ and for the diastolic measurements, $70.7 \pm 7.0$ vs. $82.3 \pm 4.9 \mathrm{mmHg}(\mathrm{P}<0.001)$.

The overall prevalence of MH was $9.2 \%$, with the SBP MH prevalence $8.2 \%$ and the DPB MH prevalence $3.1 \%$, Figure 1 . The
24h-ABPM (unpublished data) prevalence of $\mathrm{MH}$ was $14 \%$. The level of agreement between the two BP measurement methods in detecting $\mathrm{MH}$ was very good (kappa $=0.74 ; 95 \% \mathrm{CI}$ : 0.59 to 0.88 ), Table 2.

The study group was further stratified based on the OBP into systolic groups: (110-119, 120-129, and 130-139 $\mathrm{mmHg}$ ) and diastolic groups: $(75-79,80-84$, and $85-89 \mathrm{mmHg})$. The 18 patients diagnosed with DT-BP MH occurred in the pre-hypertension range: $120-139 \mathrm{mmHg}$.

\section{Discussion}

A 24-hour ABPM is the standard method to diagnose $\mathrm{MH}$. Shortened ABPM sessions, representing the results of the whole session, could possibly produce similar clinical decision-making and being more cost-effective on patients' daily lives. To provide evidence, we compared 12 hour with 24 hour monitoring to diagnose $\mathrm{MH}$, but kept in mind that the two methods are using a different cut-off value.

Prior studies reported that the average of serial BP readings obtained during a 2-hour monitoring period is a consistent predictor of the whole-day BP [9,10]. In 2008, Ernst et al. studied ABPM in 569 patients with shortened intervals of 4-, 6- and 8 hour sessions and indicated that the shortened ABPM time period of 6 to 8 hours may potentially approximate the patient's overall BP obtained from a full 24 hour average [11].

An important finding in the current study is that screening for MH may have to be extended to individuals with no cardiac risk factors. The challenge will be to decide which individual will be a candidate for such screening. Research is required to explore this under-researched topic $[11,12]$. Another contribution of the current study was using young healthy soldiers and determining the prevalence of $\mathrm{MH}$ in that sub-group.

Pairing the average OBP and DT-ABP yielded a prevalence of

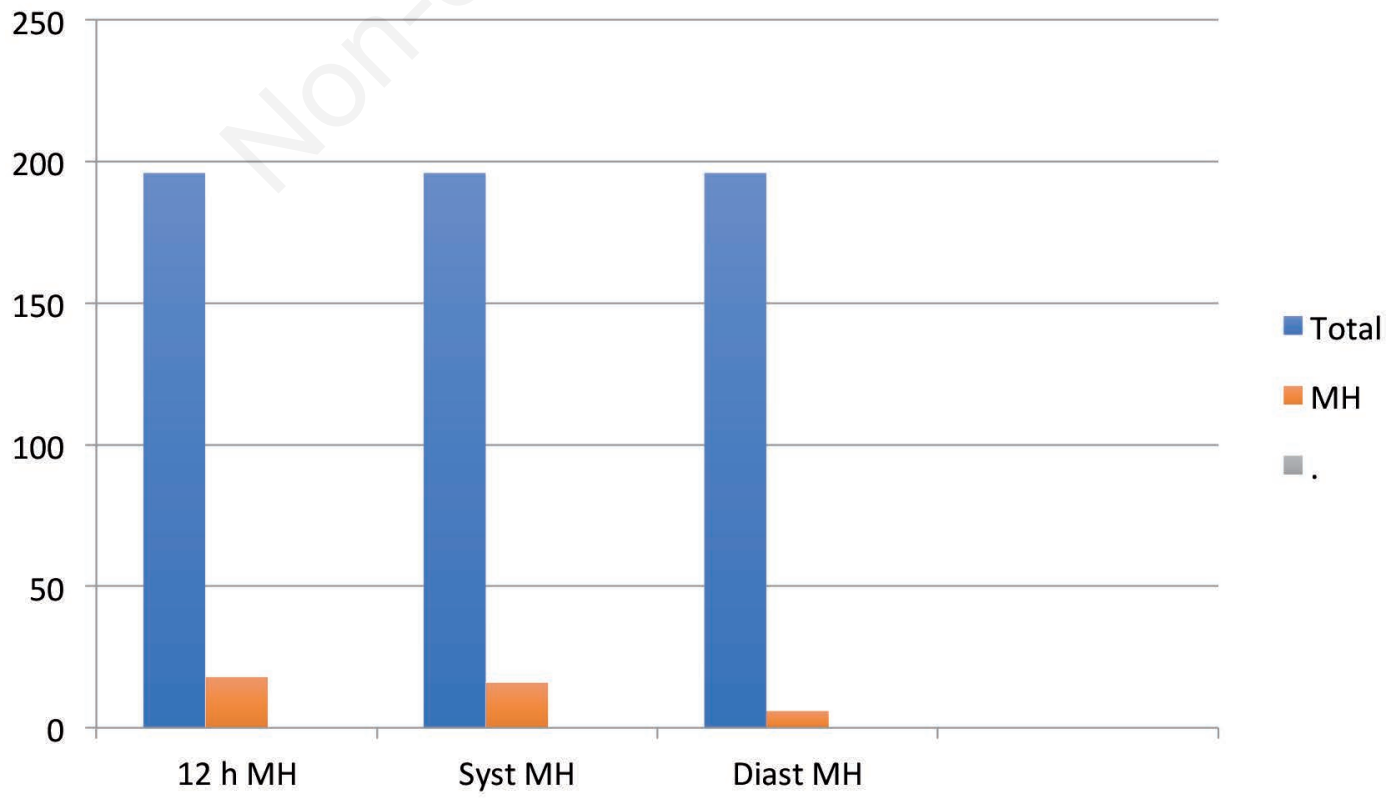

Figure 1. Masked HTN in relation to screened group. 
Table 1. Comparison of office blood pressure with DT-Masked Hypertension.

\begin{tabular}{lccc} 
& Office blood pressure & DT-Masked & \\
& & Hypertension 18 patients & \\
Mean age -years & $32.4 \pm 5.3$ & $36.3 \pm 4.6$ & $\mathrm{p}=0.018$ \\
Mean Systolic BP & $121.5 \pm 8.4$ & $139 \pm 4.8$ & $\mathrm{p}<0.001$ \\
\hline Mean Diastolic BP & $70.7 \pm 7.0$ & $82 \pm 4.9$ & \\
12- H MH & & $9.2 \%$, & \\
\hline 12-H SPB MH & & $8.2 \%$ & \\
12- H DBP MH & $3.1 \%$. & \\
\hline
\end{tabular}

Table 2. Characteristics of patients with Day time-Masked Hypertension.

\begin{tabular}{|c|c|c|c|c|c|c|c|}
\hline $\mathbf{N}$ & Age & MH based on ABP & Sys.MH & Dia.MH & Weight & BMI & Dipper /Non-Dipper \\
\hline 1) & 36 & $151 / 90$ & Yes & Yes & 66 & 27 & \\
\hline 2) & 44 & $148 / 88$ & Yes & Yes & 86 & 30 & \\
\hline 3) & 39 & $145 / 89$ & Yes & Yes & 75 & 30 & ND \\
\hline 4) & 39 & $144 / 80$ & Yes & & 113 & 41 & ND \\
\hline 5) & 35 & $142 / 83$ & Yes & & 107 & 37 & \\
\hline 6) & 30 & $139 / 83$ & Yes & & 89 & 27 & ND \\
\hline 7) & 36 & $138 / 90$ & Yes & Yes & 86 & 30 & ND \\
\hline 8) & 39 & $138 / 83$ & Yes & 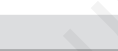 & 80 & 28 & ND \\
\hline 9) & 32 & $138 / 81$ & Yes & & 79 & 25 & D \\
\hline 10) & 28 & $137 / 80$ & Yes & 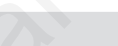 & & & D \\
\hline 11) & 41 & $137 / 79$ & Yes & 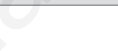 & 76 & 24 & ND \\
\hline 12) & 38 & $137 / 74$ & Yes & & 79 & 29 & ND \\
\hline 13) & 40 & $135 / 81$ & Yes & & 87 & 31 & ND \\
\hline 14) & 28 & $135 / 76$ & Yes & & 69 & & ND \\
\hline 15) & 35 & $135 / 74$ & Yes & & & & ND \\
\hline 16) & 32 & $135 / / 80$ & Yes & & 111 & 33.9 & ND \\
\hline 17) & 42 & $134 / 85$ & & Yes & & & ND \\
\hline 18) & 39 & $133 / 85$ & & Yes & & & ND \\
\hline
\end{tabular}

MH of 18/196 (9.2\%) and the best OBP cut-point for detecting $\mathrm{MH}$ was $130 / 82 \mathrm{~mm} \mathrm{Hg}$ (SBP: sensitivity $=87.5 \%$, specificity $=58.3 \%$, $\mathrm{AUC}=76.4 \pm 5.6 \%, \mathrm{CI}=65.4-87.5 \%$ and $\mathrm{P}=0.001$; DBP: sensitivity $=1.00 \%$, specificity $=73.2 \%, \mathrm{AUC}=87.9 \pm 3.7 \%$, CI: $80.6-95.2 \%$. and $\mathrm{P}=0.002$ ) with false positive rates $42 \%$ and $27 \%$; respectively. The fact that the AUC were statistically significant suggests that systolic and diastolic OBP were able to predict DT-ABP MH.

Although we used day time as a convenient method, we have to address that in a multivariable Cox model of 6 prospective studies included 7112 untreated hypertensive, night-time BP variability was an independent predictor of cardiovascular events, cardiovascular mortality and all-cause mortality. In fully adjusted models, a night-time systolic BP SD of $\geq 12.2 \mathrm{~mm} \mathrm{Hg}$ was associated with a $41 \%$ greater risk of cardiovascular events, a $55 \%$ greater risk of cardiovascular death, and a $59 \%$ increased risk of all-cause mortality while The corresponding values for a diastolic BP SD of $\geq 7.9 \mathrm{~mm} \mathrm{Hg}$ were $48 \%, 132 \%$, and $77 \%$ [13].

Our study highlighted the importance of $12 \mathrm{H}$ for improving the tolerability but the findings cannot be extended to women, as our study population was men only. Larger studies might change the recommendation in the guideline towards a day time ABP only.

\section{Conclusions}

DT-ABPM demonstrated a $9 \%$ prevalence of $\mathrm{MH}$, which was comparable to the results of $24 \mathrm{~h}-\mathrm{ABPM}$ when tested in young healthy soldiers.

\section{References}

1. Peiris D, Thompson SR, Beratarrechea A, et al GACD Hypertension Research Programme, Writing Group. Behaviour change strategies for reducing blood pressure-related disease burden: findings from a global implementation research programme. Implement Sci 2015;10:158. doi: 10.1186/s13012-015-0331-0.

2. Lacey B, Lewington S, Clarke R, et al. Age-specific association between blood pressure and vascular and non-vascular chronic diseases in 0.5 million adults in China: a prospective cohort study. The Lancet. Global Health. 
2018;6:e641-e649. DOI: 10.1016/s2214-109x 30217-1.

3. Ansarimoghaddam A, Adineh HA, Zareban I, et al. Prevalence of metabolic syndrome in Middle-East countries: Meta-analysis of cross-sectional studies. Diabetes Metab Syndr 2018;12:195-201. doi:10.1016/j.dsx.2017.11.004.

4. Whelton PK, Carey RM, Aronow WS, et al. ACC/AHA/AAPA/ABC/ACPM/AGS/APhA/ASH/ASPC/NM A/PCNA Guideline for the Prevention, Detection, Evaluation, and Management of High Blood Pressure in Adults: Executive Summary: A Report of the American College of Cardiology/American Heart Association Task Force on Clinical Practice Guidelines [published correction appears in Hypertension 2018; 71: e136-e139] [published correction appears in Hypertension 2018; 72: e33]. Hypertension 2018; 71: 1269-1324. doi: 10.1161/HYP.0000000000000066.

5. Ernst ME, Bergus GR. Favorable patient acceptance of ambulatory blood pressure monitoring in a primary care setting in the United States: a cross-sectional survey. BMC Fam Pract 2003;4:15. doi: 10.1186/1471-2296-4-15.

6. Williams B, Mancia G, Spiering W, et al. 2018 ESC/ESH Guidelines for the management of arterial hypertension [published correction appears in Eur Heart J 2019;40:475]. Eur Heart J. 2018;39:3021-104. doi: 10.1093/eurheartj/ehy339.

7. O'Brien E, Parati G, Stergiou G, et al. European Society of Hypertension position paper on ambulatory blood pressure monitoring [published correction appears in $\mathrm{J}$ Hypertens 2013;31:2467]. J Hypertens 2013;31:1731-68. doi: 10.1097/HJH.0b013e328363e964.

8. Weber MA, Drayer JIM, Wyle FA, et al. A Representative Value for Whole-Day BP Monitoring. JAMA 1982;248:16268. doi: 10.3346/jkms.1986.1.1.59.

9. Yoo WS, Park HJ, Lee EY, Choi SK. A representative value for 24-hour monitored ambulatory blood pressure. J Korean Med Sci 1986;1:59-62. doi: 10.3346/jkms.1986.1.1.59.

10. Ernst ME, Weber C, Dawson J, et al. How Well Does a Shortened Time Interval Characterize Results of a Full Ambulatory Blood Pressure Monitoring Session? J Clin Hypert 2008;10:431-5. doi: 10.1111/j.1751-7176.2008. 07784.x.

11. Franklin SS, O'Brien E, Staessen JA. Masked hypertension: understanding its complexity. Eur Heart J 2017;38:1112-8. doi: 10.1093/eurheartj/ehw502.

12. Tientcheu D, Ayers C, Das SR, et al. Target Organ Complications and Cardiovascular Events Associated With Masked Hypertension and White-Coat Hypertension: Analysis From the Dallas Heart Study. J Am Coll Cardiol 2015;66:2159-69. doi: 10.1016/j.jacc.

13. Palatini P, Reboldi G, Beilin LJ, et al. Added predictive value of night-time blood pressure variability for cardiovascular events and mortality: the Ambulatory Blood PressureInternational Study. Hypertension. 2014;64:487-93. doi: 10.1161/HYPERTENSIONAHA.114.03694. 